\title{
Enterobacteriaceae in calves, cows and milking environment may act as reservoirs of virulence and antimicrobial resistance genes
}

\author{
Camila Chioda de ALMEIDA ${ }^{1}$, Thaylane Paula FINANCI ${ }^{1}$, Marita Vedovelli CARDOZO ${ }^{1 *}$, \\ Lucas Jose Luduverio PIZAURO ${ }^{2}$ (D), Natalia PEREIRA ${ }^{1}$, Mylena Karoline VALMORBIDA ${ }^{1}$, \\ Mariana Monezi BORZI ${ }^{1}$, Bruno WEISS ${ }^{2}$, Fernando Antônio de ÁVILA ${ }^{1}$
}

\begin{abstract}
The aim of this study was to investigate the presence of virulence and antimicrobial resistance genes and clonal profile of Enterobacteriaceae isolated from calves, cows, feeding buckets and the milk bucket. A a total of 31 Enterobacteriaceae isolates from calves (6), milk bucket (6), feeding buckets (6) and from cows' rectum (13) were used. The presence of LT, STa, STb, STx1, STx2, eae, rmpA, wabG, $m r k D, k f u, m c g A$, fimH and uge as well as the antimicrobial resistance genes: AmpC MOX, FOX, MIR, ACT, DHA, ACC, CTX-M-1, CTX-M2, TEM KPC and MCR-1 and SH were evaluated by PCR. The LT toxin gene were detected in five isolates (16.1\%) and the $m r k \mathrm{D}$ gene was detected in three isolates $(9.0 \%)$. The CTX-M-1 gene was detected in 13 isolates (41.9\%), CTX-M-2 in five isolates (16.1\%) and ACC-M in four isolates (12.9\%). Most of the isolates obtained demonstrated, resistance to cephalothin $(87.5 \%)$, ampicillin, $(87.5 \%)$ and streptomycin $(84.3 \%)$ with multidrug resistance observed in all isolates. Isolates from bucket and cow's rectum, calves and milk bucket, calf and cow's rectum shared the same pulsotypes. These findings may suggest that enterobacteria carring virulence and resistance genes may persist in the environment and became a reservoir of these genes.
\end{abstract}

Keywords: E. coli; K. pneumoniae; antibiotic; milk.

Practical Application: In this study, the role of Enterobacteriaceae in calves, cows and milking environment acting as a reservoirs of virulence and antimicrobial resistance genes were evaluated. Isolates in this study possessed virulence and antimicrobial resistance genes and were distributed throughout animals and environment and they also shared similarities in their pulsotype indicating a possible relationship and that they indeed may act as a reservoir and shared virulence genes.

\section{Introduction}

Usually, an "indicator organism" reflects the microbial condition of a food or environment (Chapin et al., 2014). For example, coliforms have been used as milk fecal contamination indicator, identifying unsanitary condition in pasteurized products and other foods (Sánchez-Gamboa et al., 2018). In addition, some coliforms have emerged as potential opportunistic pathogens due to the acquisition of virulence and antibiotic resistance factors though mobile genetic elements (Ntuli et al., 2016). The focus of the majority of published articles rely on bulk milk samples with information available on the environment, animals or milk bucket as a potential reservoir for contamination of Enterobacteria is scarce (Mullan, 2019). This family includes important zoonotic bacterial pathogens such as Salmonella spp. and E. coli (Kamana et al., 2017) and have been reported to have several important virulence genes including: thermolabile toxin (LT), thermostable toxin (STa and STb), shiga like toxin (Stx1 and Stx2), attaching and effacing (Eae) and also rmpA (regulator of mucoid phenotype), wabG (lipopolysaccharides), $m r k \mathrm{D}$ (biofilm), $k f u$ (iron uptake), magA (mucus viscosity), fim $\mathrm{H}$ (fimbriae) and uge (lipopolysaccharides) been detected in Klebsiella pneumoniae (Jian-li et al., 2017). In addition, antibiotic resistance genes encoding AmpC enzymes in Enterobacteriaceae are both chromosomally and plasmid mediated which increase its potential for lateral transfer (Khari et al., 2016). The extended spectrum $\beta$-lactamase group capable of hydrolysing penicillin and cephalosporin are encoded by CTX-M-1, CTX-M2, TEM, SHV and carbapenem resistance though KPC (Khari et al., 2016) with recently, antimicrobial resistance has been reported from bacteria isolated from dairy products related to pathogenic agents such as E. coli and Salmonella spp. (Hleba et al., 2015). However, there is little information about Enterobacteriaceae from animals, milk or the milking environment. Therefore, the aim of this study was to investigate the presence of virulence and antimicrobial resistance factors in Enterobacteria isolated from healthy calves and cows, feeding buckets and the milk bucket.

\section{Materials and methods}

The samples were obtained from the dairy farm at the São Paulo State University. This farm is a small herd consisting of 17 cows that are milked twice a day, in a semi-intensive

${ }^{1}$ Departamento de Patologia Veterinária, Faculdade de Ciências Agrárias e Veterinárias, Universidade Estadual Paulista - Unesp, Campus de Jaboticabal, Jaboticabal, SP, Brasil

${ }^{2}$ Departamento de Técnologia, Faculdade de Ciências Agrárias e Veterinárias, Universidade Estadual Paulista - Unesp, Campus de Jaboticabal, Jaboticabal, SP, Brasil

*Corresponding author: maritavedovelli@yahoo.com.br 
system. Animals are fed with both pasture and silage. Swab samples were collected from the rectum of six calves and from 13 lactating cows, as well as from the milk bucket and the calves' feeding bucket. These swabs were subsequently added to the swab recipient containing Stuart medium and transported to the laboratory. Isolation and identification of Enterobacteriaceae spp. were done according to (Quinn et al., 2005) using MacConkey, Brilliant green, and XLT4 agar and biochemical test. Bacterial DNA extraction was done according to (Keskimäki et al., 2001), and the virulence gene detection by PCR was performed as described by (China et al., 1996). After the amplification, products were visualized by gel electrophoresis. The following virulence genes were analyzed $L T$, $S T a, S T b$, stx1, stx2, eae, rmpA, wabG, $m r k D, k f u, m c g A$, fimH and $u g e$. To detect antimicrobial resistance genes, the different types of genes encoding AmpC type resistance (MOX, FOX, MIR, ACT, DHA, ACC) and resistance to ESBL by CTX-M-1, CTX-M2, TEM, SHV gene were evaluated by PCR as described by (Dierikx et al., 2013). In addition, carbapenemase enzyme production (KPC), and resistance to colistin (MCR-1) were also evaluated. Antimicrobial sensitivity was evaluated using the (Kirby Bauer) test according to the Clinical and Laboratory Standards Intitute (Wikler et al., 2007). The antibiotics tested were selected by their importance in the dissemination of resistance genes: ampicillin (10 mg), cephalothin (30 mg), streptomycin (10 mg), gentamicin, (10 mg), amoxicillin + clavulanic acid $(30 \mathrm{mg})$, norfloxacin (10 mg), amikacin (30mg), Fosfomycin (200 mg), nitrofurantoin $(300 \mathrm{mg})$, cefoxitin $(30 \mu \mathrm{g})$, ceftazidime $(30 \mu \mathrm{g})$. Isolates pulsotypes identification was done according to the procedure established by the Centers for Disease Control (CDC) (Ribot et al., 2006). A Salmonella Braenderup strain (Adolfo Luts Institute of São Paulo) was used as a standard marker for the PulseNet protocol. The fragments similarity was compared using the Dice coefficient at $1 \%$ tolerance and $1 \%$ optimization and dendrograms were constructed using the Neighbor-Joining grouping method using the program BioNumerics 7.1.

\section{Results and discussion}

Although E. coli is the most common gram negative bacteria that causes subclinical mastitis, and exibits antibiotic resistance, presence of pathogenic $E$. coli in the environment is often overlooked (Hinthong et al., 2017). Existence of pathogenic E. coli in environmental sources and from milk from subclinical mastitis affected cows have been show before by the detection of especific virulence genes (Hinthong et al., 2017). Therefore, among the total of 31 Enterobacteriaceae isolates obtained that were six from calves, six from the final milk unit, six from the feeding buckets and 13 from cow's rectum. The LT gene was detected in five isolates, one from a calf and four from the milk bucket. The $m r k \mathrm{D}$ gene was also detected in three isolates, two from calves and one from cow's rectum. None of the isolates were positive for the $s t a, s t b, s t x 1, s t x 2$, eae, rmpA, wabG, kfu mcgA fimH or uge genes. The CTX-M-1 gene was detected in 13 isolates, two from calves and 11 from cows while the CTX-M-2 gene was detected in five isolates from calves (2), milk bucket (1), feeding bucket (1) and cow (1). The ACC-M gene were detected in four isolates, two from calves, one from feeding bucket and one from cow. None of the isolates were found to be resistant to TEM, TEM1, SHV1, FOX-M, MOX-M, DHA, CIT-M, EBC-M, CLR or KCP (Table 1).

Since this study was conducted on a small and controlled university herd, associated with a small dairy facility, these results should be analyzed in detail and carefully. Nevertheless, day to day dairy activities are practiced in the university facility and thus, subject to the same problems that are present into the small farm dairy industry. Although occurrence of coliforms in milk has been linked to unhygienic processing condition that will result in decreased sensory score of pasteurized milk and reduce its shelf life (Masiello et al., 2016), recent finding suggest that a fraction is of fecal origin while the rest is mostly from the environment (Martin et al., 2016).

In this regard, in the current study, Enterobacteriaceae isolated from calves, cows and feeding bucket presented a similarity of $>65 \%$ while the isolates from cows' rectum and the milk bucket shared similarities higher than $75 \%$ suggesting that indeed, the environmental isolates could be a key element for the milk contamination. Also, since isolates that share a $65 \%$ or more degree of similarity were found with the cow, calf and the feeding bucket, a cycle of re-contamination or even horizontal transmission could be attributed to the environment. This could associated with the fact that management practice at the farm, including milking machine wash failures, the rate of clusters washes and rate of milking unit fall-off during milking is correlated with the level of coliform in milk (Martin et al., 2016).

The isolates demonstrate resistance to the antimicrobial tested, $90 \%$ (30/31) were resistant to cephalothin $87.5 \%(28 / 31)$ were resistant to ampicillin, 87.5 (28/31) to streptomycin, $84.3 \%(27 / 31)$ to nitrofurantoin, $78,1 \%(25 / 31)$ to amikacin, $71,8 \%(23 / 31)$ to gentamicin, $68,7 \%(22 / 31)$ to cephalothin, $56.2 \%(18 / 31)$ to fosfomycin, $50.0 \%(16 / 31)$ to amoxicillin with clavulanic acid, $46.8 \%$ (15/31) to norfloxacin, $43.7 \%$ (14/31) to ceftazidime. Multidrug resistance was observed in all isolates, with seven (21.8\%) isolates been resistance to eleven antibiotics, five (15.6\%) been resistant to ten, five (15.6\%) to nine, four (12.5) to eight, one (3.12\%) to seven, three (9.37\%) to six, four (12.5\%) to five, two $(6.25 \%)$ to three and one $(3.12 \%)$ to two antibiotics simultaneously.

It was possible to observe two distinct groups ( $>55 \%$ similarity) and 20 distinct pulsotypes with a similarity rate that ranged from (55 to 75\%) (Figure 1). Demonstrating that there is no clone dominating the environment. Isolates from the cow's rectum presented $70 \%$ similarity with isolates from the final milking unit. Also, similarities higher than $65 \%$ were observed between isolates from calves, cows and the feeding bucket which suggest that an endemic circle could be associated within the enterobacteria in the dairy farm. Antibiotic resistance in the isolates tested was widespread, with $90 \%$ been resistant to cephalothin, $87.5 \%$ to ampicillin, 87.5 to streptomycin, $84.3 \%$ to nitrofurantoin, $78.1 \%$ to amikacin, $71.8 \%$ to gentamicin, $68.7 \%$ to cephalothin. A lower 
Table 1. Origin, pulsotype, virulence and antibiotic resistance genes and antibiotic resistance of isolates obtained from calves, milk bucket, feeding buckets and from cows.



${ }^{*}$ CO: Cow; FMU: final milking unit; CA: calf; BU: Bucket; ${ }^{\circledR}$ STR: Streptomycin; AMC: amoxicillin + clavulanic; NOR: Norfloxacin; GEM: gentamicin; AMK: amikacin; FOS: Fosfomycin; AMP: ampicillin; FOX: Cefoxitin; NIT: nitrofurantoin; CEF: cephalothin; CAZ: ceftazidime; ${ }^{*}$ Four isolates $(2,11,15$ and 31$)$ which were negative for all genes tested and which were not antibiotic resistant were not included in this table.

frequency of isolates were resistance to fosfomycin (56.2\%), to amoxicillin with clavulanic acid (50.0\%), norfloxacin (46.8\%), and $43.7 \%$ to ceftazidime. Although enterococci are known to have low-level resistance to the aminoglycosides, in this study $87.5 \%$ of the isolates were resistant to streptomycin and $68.7 \%$ were resistant to gentamicin. For the successful treatment of enterococci infection, aminoglycosides are often used (Hammad et al., 2015) and resistance to gentamicin would render this association ineffective. Also, due to the fact that all samples presented a degree of multidrug resistance, with a large amount of isolates harboring resistant to almost all antibiotic tested, associated with the fact that this milk could be used for raw milk cheese production, especially in area with the geographic habit of appreciation of these products such as Egypt (Hammad et al., 2015) or Brazil.

Detection of isolates that possess the E. coli labile toxin genes from calves and from the milk bucket are of concern. The milk from the milk bucket will go the bulk tank and could be sold as raw or pasteurized. If sold raw for raw milk cheese production, it could be the cause of foodborne diseases. According to (Whitehead \& Lake, 2018) consumption of raw milk product is a growing trend in North America and Europe. The LT positive strains were group together with LT negative strains and thus meaning that they could eventually acquire this virulence gene since they are already similar. 


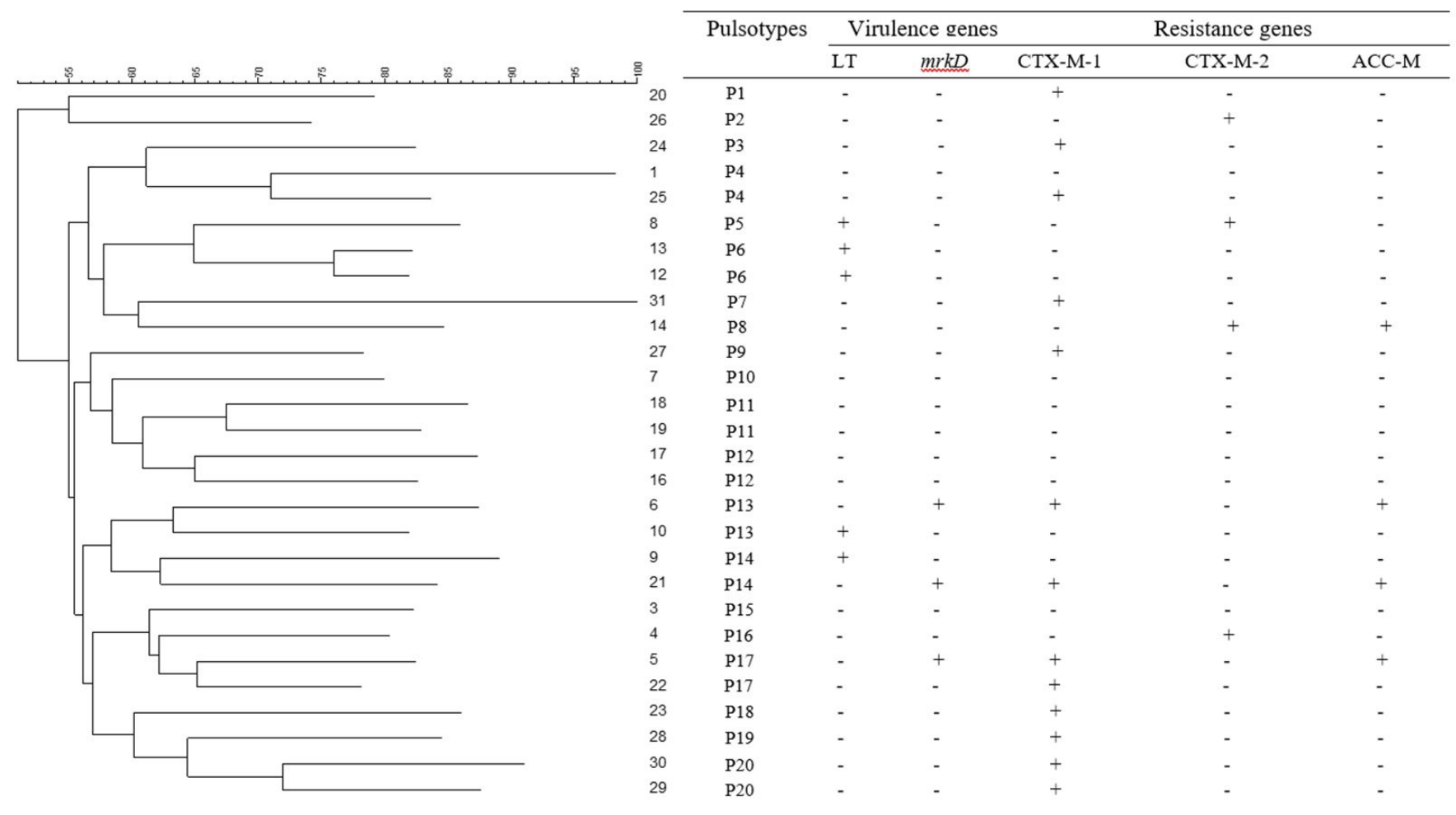

Figure 1. Isolates pulsotypes clusters and their respective virulence and antibiotic resistance genes. Isolates $2,11,15$ could not be restricted by $\mathrm{Xba}$ I enzyme and thus not present at the dendrogram.

\section{Conclusion}

In conclusion, in this study it was observed that Enterobacteriacea spp. isolates from environment, animals' rectum and the milk bucket shared some similarities in their respective pulsotypes. Thus, this indicate that indeed, Enterobacteriaceae could act as a reservoir of virulence and antibiotic resistance gene for other pathogenic species such as E. coli in the milking environment.

\section{Acknowledgements}

To the financial support of the "Fundação de Amparo em Pesquisa do Estado de São Paulo" FAPESP protocol number: 2019/02164-7.

\section{References}

Chapin, T. K., Nightingale, K. K., Worobo, R. W., Wiedmann, M., \& Strawn, L. K. (2014). Geographical and Meteorological Factors Associated with Isolation of Listeria Species in New York State Produce Production and Natural Environments. Journal of Food Protection, 77(11), 1919-1928. http://dx.doi.org/10.4315/0362-028X. JFP-14-132. PMid:25364926.

China, B., Pirson, V., \& Mainil, J. (1996). Typing of bovine attaching and effacing Escherichia coli by multiplex in vitro amplification of virulence-associated genes. Applied and Environmental Microbiology, 62(9), 3462-3465. http://dx.doi.org/10.1128/AEM.62.9.34623465.1996. PMid:8795238.

Dierikx, C., van der Goot, J., Fabri, T., van Essen-Zandbergen, A., Smith, H., \& Mevius, D. (2013). Extended-spectrum- $\beta$-lactamase- and
AmpC- $\beta$-lactamase-producing Escherichia coli in Dutch broilers and broiler farmers. The Journal of Antimicrobial Chemotherapy, 68(1), 60-67. http://dx.doi.org/10.1093/jac/dks349. PMid:22949623.

Hammad, A. M., Hassan, H. A., \& Shimamoto, T. (2015). Prevalence, antibiotic resistance and virulence of Enterococcus spp. in Egyptian fresh raw milk cheese. Food Control, 50, 815-820. http://dx.doi. org/10.1016/j.foodcont.2014.10.020.

Hinthong, W., Pumipuntu, N., Santajit, S., Kulpeanprasit, S., Buranasinsup, S., Sookrung, N., Chaicumpa, W., Aiumurai, P., \& Indrawattana, N. (2017). Detection and drug resistance profile of Escherichia coli from subclinical mastitis cows and water supply in dairy farms in Saraburi Province, Thailand. PeerJ, 2017(6), e3431. http://dx.doi. org/10.7717/peerj.3431. PMid:28626609.

Hleba, L., Petrová, J., Kántor, A., Čuboň, J., \& Kačániová, M. (2015). Antibiotic resistance in Enterobacteriaceae strains isolated from chicken and milk samples. Journal of Microbiology, Biotechnology and Food Sciences, 4(Special 01), 19-22. https://doi.org/10.15414/ jmbfs.2015.4.special1.19-22

Jian-li, W., Yuan-yuan, S., Shou-yu, G., Fei-fei, D., Jia-yu, Y., Xue-hua, W., Yong-feng, Z., Shi-jin, J., \& Zhi-jing, X. (2017). Serotype and virulence genes of Klebsiella pneumoniae isolated from mink and its pathogenesis in mice and mink. Scientific Reports, 7(1), 1-7. http://dx.doi.org/10.1038/s41598-017-17681-8. PMid:29230010.

Kamana, O., Jacxsens, L., Kimonyo, A., \& Uyttendaele, M. (2017). A survey on hygienic practices and their impact on the microbiological quality and safety in the Rwandan milk and dairy chain. International Journal of Dairy Technology, 70(1), 52-67. http://dx.doi.org/10.1111/14710307.12322 .

Keskimäki, M., Eklund, M., Pesonen, H., Heiskanen, T., \& Siitonen, A. (2001). EPEC, EAEC and STEC in stool specimens: Prevalence and molecular epidemiology of isolates. Diagnostic Microbiology 
and Infectious Disease, 40(4), 151-156. http://dx.doi.org/10.1016/ S0732-8893(01)00265-6. PMid:11576786.

Khari, F. I. M., Karunakaran, R., Rosli, R., \& Tay, S. T. (2016). Genotypic and phenotypic detection of AmpC $\beta$-lactamases in Enterobacter spp. Isolated from a teaching hospital in Malaysia. PLoS One, 11(3), 1-12. http://dx.doi.org/10.1371/journal.pone.0150643. PMid:26963619.

Martin, N. H., Trmcic, A., Hsieh, T. H., Boor, K. J., \& Wiedmann, M. (2016). The evolving role of coliforms as indicators of unhygienic processing conditions in dairy foods. Frontiers in Microbiology, 7(SEP), 1-8. http://dx.doi.org/10.3389/fmicb.2016.01549. PMid:27746769.

Masiello, S. N., Martin, N. H., Trmčić, A., Wiedmann, M., \& Boor, K. J. (2016). Identification and characterization of psychrotolerant coliform bacteria isolated from pasteurized fluid milk. Journal of Dairy Science, 99(1), 130-140. http://dx.doi.org/10.3168/jds.20159728. PMid:26547640.

Mullan, W. M. A. (2019). Are we closer to understanding why viable cells of Mycobacterium avium subsp. paratuberculosis are still being reported in pasteurised milk? International Journal of Dairy Technology, 72(3), 332-344. http://dx.doi.org/10.1111/1471-0307.12617.

Ntuli, V., Njage, P. M. K., \& Buys, E. M. (2016). Characterization of Escherichia coli and other Enterobacteriaceae in producer-distributor bulk milk. Journal of Dairy Science, 99(12), 9534-9549. http://dx.doi. org/10.3168/jds.2016-11403. PMid:27720154.
Quinn, P. J., Markey, B. K., Carter, M. E., Donnelly, W. J., \& Leonard, F. C. (2005). Microbiologia veterinária e doenças infecciosas (1st ed.). Porto Alegre: Artmed.

Ribot, E. M., Fair, M. A., Gautom, R., Cameron, D. N., Hunter, S. B., Swaminathan, B., \& Barrett, T. J. (2006). Standardization of PulsedField Gel Electrophoresis Protocols for the Subtyping of Escherichia coli O157:H7, Salmonella, and Shigella for PulseNet. Foodborne Pathogens and Disease, 3(1), 59-67. http://dx.doi.org/10.1089/ fpd.2006.3.59. PMid:16602980.

Sánchez-Gamboa, C., Hicks-Pérez, L., Gutiérrez-Méndez, N., Heredia, N., García, S., \& Nevárez-Moorillón, G. V. (2018). Seasonal influence on the microbial profile of Chihuahua cheese manufactured from raw milk. International Journal of Dairy Technology, 71, 81-89. http:// dx.doi.org/10.1111/1471-0307.12423.

Whitehead, J., \& Lake, B. (2018). Recent trends in unpasteurized fluid milk outbreaks, legalization, and consumption in the United States. PLoS Currents, 10. PMid:30279996.

Wikler, M. A., Cockerill, F. R., Craig, W. A., Dudley, M. N., Eliopoulos, G. M., Hecht, D. W., Hindler, J. F., Low, D. E., Sheehan, D. J., Tenover, F. C., Turnidge, J. D., Weinstein, M. P., Zimmer, B. L., Ferraro, M. J. \& Swenson, J. M. (2007). Performance Standards for Antimicrobial Susceptibility Testing. Clinical and Laboratory Standars Institute. 27(Issue 1):1-177. 